\title{
Value of a lateral inferior pedicle flap in Draf Illb for recurrent frontal sinus diseases: a prospective study
}

\author{
Chao $\mathrm{He}^{1}$ (i) $\cdot$ Hong-Tao Zhen ${ }^{1}$ (D)
}

Received: 23 August 2021 / Accepted: 7 February 2022 / Published online: 26 February 2022

(c) The Author(s) 2022

\begin{abstract}
Purpose The Draf IIb procedure allows the widest unilateral access to the frontal sinus in a minimally invasive fashion, with efficiency and safety comparable to the Draf III. However, this technique is still associated with a high postoperative stenosis rate. The exposure of drilled bone induces osteitis predisposing to scarring and neo-osteogenesis causing ostium restenosis. We developed a novel lateral inferior pedicle flap (LIPF) to cover the exposed bone and prevent restenosis during Draf IIb. We aimed to describe our technique.

Methods Adult patients requiring a Draf IIb for unilateral recurrent frontal sinus disease were prospectively enrolled. A LIPF technique was systematically performed. Demographics and complications were recorded. The primary outcome measure was neo-ostium patency at 12 months. In patients with chronic rhinosinusitis (CRS), the clinical control rate was evaluated at 12 months.

Results 59 patients underwent the Draf IIb with LIPF technique from 2013 to 2021.49 patients ( 20 women/29 men, median age of 48.0 years) completed at least 12 months of follow-up (median 41.0 months, range 12-100 months). Indications included recalcitrant CRS $(n=32)$, inverted papilloma $(n=9)$ and frontal mucocele $(n=8)$. Overall, the neo-ostium remained patent at 12 months in all patients, and the clinical control rate of 32 patients with recalcitrant CRS at 12 months was $100 \%$. No main complications were recorded.
\end{abstract}

Conclusion The LIPF technique was associated with a high rate of success for a Draf IIb.

Keywords Endoscopic sinus surgery $\cdot$ Frontal sinus $\cdot$ Draf IIb $\cdot$ Restenosis $\cdot$ Lateral inferior pedicle flap

\section{Introduction}

Despite the major progress in endoscopic approaches, instrumentations and image guidance systems, the endoscopic surgical management of the frontal sinus remains a challenge to surgeons due to the numerous anatomic variations, difficult surgical access, and tendency of restenosis during the follow-up period [1,2].

Extended frontal approaches, as described by Draf, Gross, and Lothrop, can often improve long-term frontal sinus

Hong-Tao Zhen

zhtlancet@sina.com

Chao He

hechaoent@163.com

1 Department of Otolaryngology-Head and Neck Surgery, Tongji Hospital, Tongji Medical College, Huazhong University of Science and Technology, No. 1095 Jiefang Avenue, Wuhan 430030, People's Republic of China patency and surgical outcomes [3, 4]. For advanced frontal sinus pathologies (recalcitrant chronic frontal sinusitis, mucocele, cerebrospinal fluid leak, inverted papilloma, and others), the two main endoscopic surgical options are the Draf IIb and Draf III procedures.

The Draf IIb procedure allows the widest unilateral access to the frontal sinus by extending the resection medially to the middle turbinate toward the nasal septum. The wide approach to the frontal sinus is obtained by drilling the frontal process of the maxilla laterally and the nasofrontal beak anteriorly [5]. The Draf III procedure is a bilateral Draf IIb with a superior and inter-sinus septectomy [6]. At present, reports on Draf IIb procedures are scarce, because the Draf III procedure is most often favored, although it is more aggressive, with the solid evidence on its safety and efficacy [7, 8]. However, recent studies have confirmed the efficiency and safety of Draf IIb procedure comparable to the Draf III $[9,10]$. 
The Draf IIb and III procedures have solved the previously mentioned problems by providing better visualization and approach to the frontal sinus and to maximize the size of the created neo-ostium of the frontal sinus, but some limitations remain $[3,4,7]$. Postoperative restenosis after the Draf procedure remains a major problem. The exposure of drilled bone in the Draf IIb and III procedure tends to induce osteitis predisposing to scarring and neo-osteogenesis which causes ostium restenosis [11-14]. To speed up mucosal healing and prevent osteitis, mucosa flaps can be used to cover exposed bone [15]. Several mucosal flaps applied to Draf procedures were reported varied from free grafts to pedicled flaps $[2,5,11,16-20]$. A free graft is easy to manipulate but is lacking in viability. A pedicled flap is robust and difficult to manipulate, and usually disturbs the operative field [2].

We describe a modification of the Draf IIb procedure for unilateral recurrent frontal sinus diseases, in which a lateral inferior pedicle flap (LIPF) is used to potentially decrease postoperative ostium stenosis. The main objective of the present study was to prospectively evaluate postoperative stenosis regarding this novel technique.

\section{Patients and methods}

\section{Patients' selection}

This is a prospective study approved by the Ethical Committee of Tongji Hospital, Tongji Medical College, Huazhong University of Science and Technology. Adult patients ( $>18$ years) undergoing the Draf IIb procedure for recurrent frontal sinus diseases (2013-2021) were enrolled. All patients had been treated with at least one previous endoscopic surgery. Diagnosis was confirmed by symptoms and high-resolution CT scans (Fig. 1). During the study period, a LIPF technique was systematically performed unless a technical limitation was encountered or in the presence of an unhealthy flap mucosa due to severe polyposis or fibrosis. Demographics and indications for surgery were collected. Patients were sorted by operation time.

\section{Surgical technique}

Procedures were performed under general anesthesia with orotracheal intubation. Mucosal decongestion was obtained with cotton wool soaked with $0.05 \%$ xylometazoline solution. The image guidance (Medtronic Navigation, Inc) was used.

A LIPF was raised after a standard uncinectomy and ethmoidectomy. A vertical incision was made approximately $10 \mathrm{~mm}$ anterior to the axilla of the middle turbinate, extending downward to the dorsum of the inferior turbinate parallel to the maxillary line and upward to the roof of nasal cavity (Fig. 2A). Then, from the upper extremity, this incision ran around the agger nasi, across the axilla (Fig. 2B), and downward following the maxillary line. It was worth noting that, for the cases with adequate and healthy middle turbinate, this incision should extend to the medial surface of the middle turbinate to retain as much of the medial mucosa of the middle turbinate as possible to ensure the length of the flap. Meanwhile, for the cases without sufficient available middle turbinate mucosa, free mucosal graft was used as supplement. The flap was elevated in a subperiosteal plane toward the dorsum of the inferior turbinate and then folded and placed in the inferior part of the nasal cavity during the subsequent steps (Fig. 2C). Elevation of this flap was followed by a standard Draf IIb procedure. A wide neo-ostium more than $5 \mathrm{~mm}$ was obtained by resection of the floor of the frontal sinus between the lamina papyracea laterally and the nasal septum medially ahead of the ventral margin of the olfactory fossa. The top and anterior walls of the frontal sinus were exposed by drilling the frontal process of the maxilla laterally and the nasofrontal beak anteriorly. At the end of the surgery, the LIPF was unfolded to cover as much of the exposed bone as possible (Fig. 2D). A nasopore was used to stabilize the flap (Fig. 2E). A schema of the flap was shown in Fig. 2F.

\section{Follow-up and outcome measures}

All patients were instructed to perform nasal saline irrigation three times a day for 1 month. For patients with recalcitrant chronic rhinosinusitis (CRS), nasal nebulization inhalation of budesonide $(1 \mathrm{ml}=1 \mathrm{mg})$ was applied once a day after
Fig. 1 (A) Axial, (B) coronal and $(\mathrm{C})$ sagittal paranasal sinus CT images of a patient with recurrent frontal sinus inverted papilloma who suffered by persistent headache
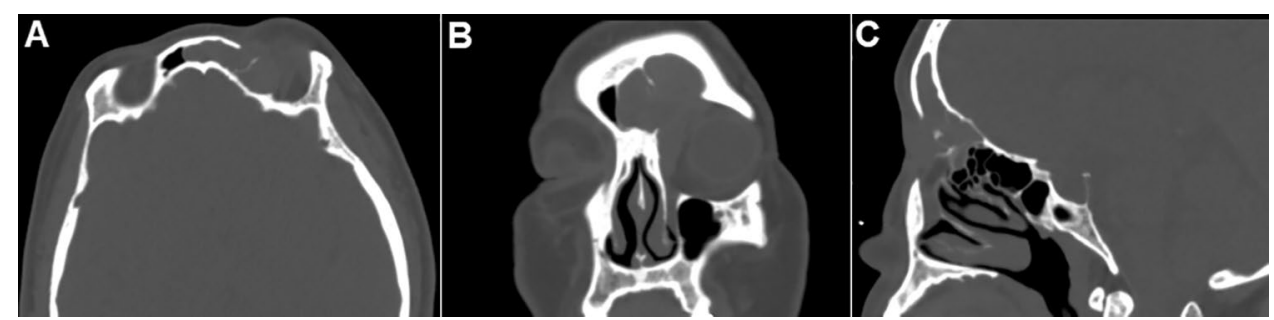
Fig. 2 Intraoperative and postoperative endoscopic views of the LIPF technique in the left nasal cavity. (A) A vertical incision was made approximately $10 \mathrm{~mm}$ anterior to the axilla of the middle turbinate. (B) This incision ran around the agger nasi and across the axilla. (C) The flap was elevated towards the dorsum of the inferior turbinate. (D) The flap was unfolded to cover the exposed bone.

(E) A nasopore was used to stabilize the flap. (F) A schema of the flap is shown. The blue dotted line shows the incision, and the red solid line shows the flap covering the exposed bone
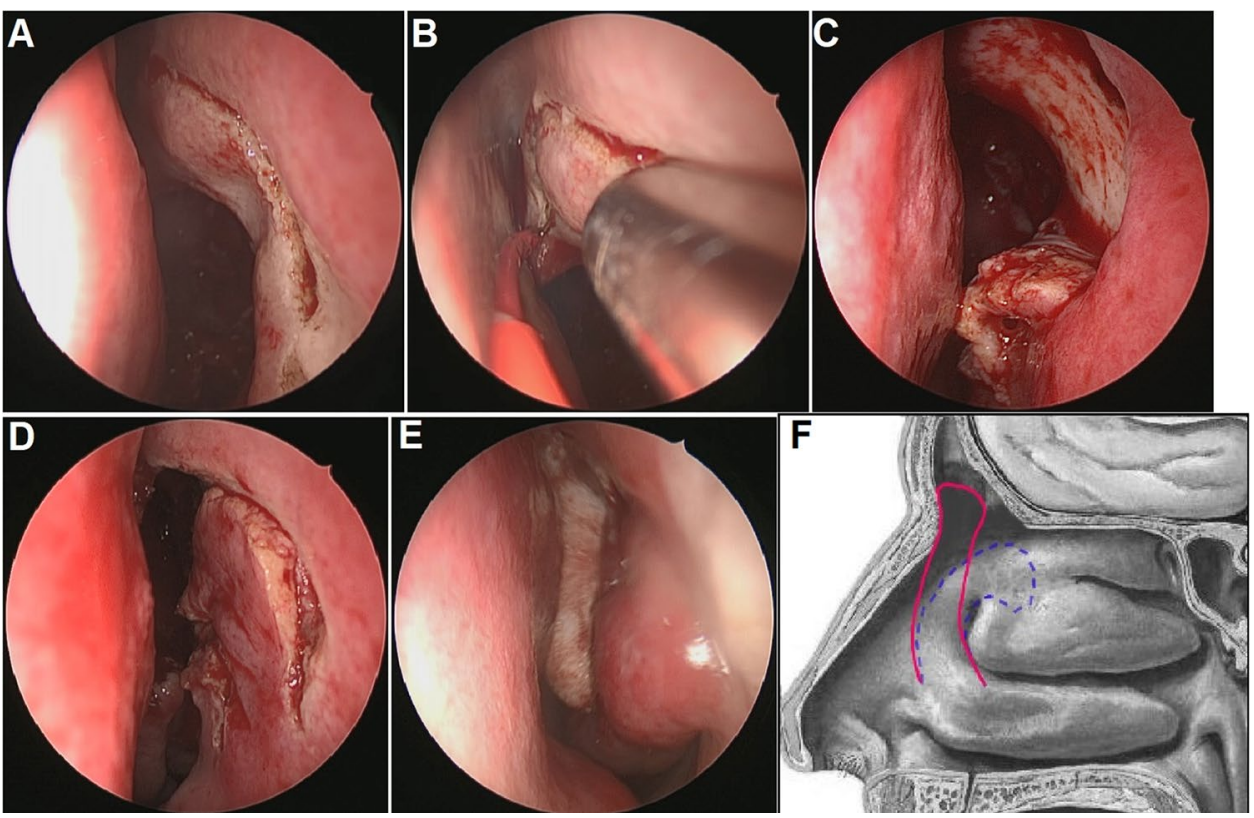

the nasal packing removal at 1 weeks and was continued for at least 3 weeks as described in our previous study [21].

Patients were followed-up for at least 12 months. Complications during the operation and follow-up period were recorded.

The primary outcome measure was postoperative neoostium patency at a minimum follow-up of 12 months. The ostium patency was defined as the ability to visualize into the frontal sinus by endoscopic examination, and follow-up CT scan was also used to aid in evaluating ostium patency. Failure was defined as complete closure of the frontal cavity or recurrence of disease requiring rescue surgery.

In patients with recalcitrant CRS, the surgical outcome was evaluated with the clinical control rate at 12 months, including evaluation of symptom and endoscopy. Symptom evaluation and endoscopy were conducted at baseline and follow-up. Symptoms including nasal obstruction, rhinorrhea/postnasal drip, facial pain/pressure, hyposmia, and sleep disturbance/fatigue were scored by visual analog scale (VAS) from 0 to 10 , with 0 indicating "no complaint whatsoever" and 10 indicating "the worst imaginable complaint" [22]. Endoscopic physical findings were scored according to the Lund-Kennedy scoring system. Clinical control of CRS was categorized as controlled, partly controlled, or uncontrolled, according to EPOS 2012 [22]. Controlled disease is defined as presenting no bothersome symptoms (VAS score $\leq 5$ ), with healthy, or almost healthy mucosa, and no need for systemic medicine to control the disease. Partly controlled patients experience fewer than 2 of the following: nasal blockage; rhinorrhea or postnasal drip; facial pain or pressure; impaired smell; sleep disturbance or fatigue; diseased mucosa on endoscopy; and a need for rescue treatment within the previous 6 months. Uncontrolled disease is defined as having $\geq 3$ of the aforementioned conditions, despite rescue treatment [22]. Clinical control rate is defined as $[($ controlled + partly controlled $) /$ total $] \times 100 \%$.

\section{Statistical analysis}

Data were analyzed using the SPSS version 23.0 (IBM Corp, Armonk, NY). Data distribution was tested for normality using the Kolmogorov-Smirnov test. Because the continuous variables were not normally distributed, they are reported as median and the first and third quartiles. The Wilcoxon signed rank test was applied for comparisons between groups. Significance was accepted at $P<0.05$.

\section{Results}

\section{Patients' characteristics}

59 patients underwent the Draf IIb procedure with LIPF technique for unilateral recurrent frontal sinus diseases by a single surgeon from 2013 to 2021.49 patients (20 women/29 men) with a median age of 48.0 years (range 19-83 years) completed at least 12 months of follow-up (median 41.0 months, range 12-100 months) and were included in the analysis (demographic and clinical characteristics of the series are presented in Table 1). Indications included recalcitrant CRS $(n=32)$, inverted papilloma $(n=9)$ and frontal mucocele $(n=8)$. The lesion was 
Table 1 Demographic and clinical characteristics of the patients

\begin{tabular}{|c|c|c|c|c|c|c|c|}
\hline Case no. & Side & Age (years) & Sex & Indication & Comorbidity & Concomitant operation & $\begin{array}{l}\text { Follow-up } \\
\text { (months) }\end{array}$ \\
\hline 1 & $\mathrm{~L}$ & 50 & M & IP & - & - & 100 \\
\hline 2 & $\mathrm{~L}$ & 40 & $\mathrm{M}$ & IP & - & - & 92 \\
\hline 3 & $\mathrm{R}$ & 48 & M & IP & - & - & 84 \\
\hline 4 & $\mathrm{~L}$ & 41 & M & IP & - & - & 80 \\
\hline 5 & $\mathrm{~L}$ & 52 & $\mathrm{~F}$ & IP & - & - & 75 \\
\hline 6 & $\mathrm{R}$ & 56 & $\mathrm{~F}$ & CRS & $\mathrm{OC}$ & - & 65 \\
\hline 7 & $\mathrm{R}$ & 56 & $\mathrm{~F}$ & Mucocele & $\mathrm{OC}$ & - & 65 \\
\hline 8 & $\mathrm{R}$ & 83 & $\mathrm{~F}$ & CRS & - & - & 63 \\
\hline 9 & $\mathrm{R}$ & 83 & $\mathrm{~F}$ & Mucocele & $\mathrm{OC}$ & - & 63 \\
\hline 10 & $\mathrm{~L}$ & 38 & M & CRS & - & - & 61 \\
\hline 11 & $\mathrm{~L}$ & 41 & M & CRS & - & - & 60 \\
\hline 12 & $\mathrm{R}$ & 33 & M & Mucocele & $\mathrm{OC}$ & - & 60 \\
\hline 13 & $\mathrm{~L}$ & 32 & M & CRS & - & - & 59 \\
\hline 14 & $\mathrm{~L}$ & 41 & M & CRS & $\mathrm{OC}$ & - & 57 \\
\hline 15 & $\mathrm{R}$ & 63 & $\mathrm{~F}$ & CRS & OC & - & 56 \\
\hline 16 & $\mathrm{~L}$ & 19 & M & CRS & - & - & 54 \\
\hline 17 & $\mathrm{~L}$ & 30 & $\mathrm{~F}$ & CRS & $\mathrm{OC}$ & - & 53 \\
\hline 18 & $\mathrm{R}$ & 37 & M & IP & $\begin{array}{l}\text { Malignancy, intrac- } \\
\text { ranial invasion }\end{array}$ & Craniotomy & 50 \\
\hline 19 & $\mathrm{~L}$ & 26 & M & Mucocele & OC & - & 45 \\
\hline 20 & $\mathrm{R}$ & 48 & M & IP & - & - & 45 \\
\hline 21 & $\mathrm{~L}$ & 50 & M & CRS & - & - & 44 \\
\hline 22 & $\mathrm{~L}$ & 46 & $\mathrm{M}$ & CRS & - & - & 44 \\
\hline 23 & $\mathrm{~L}$ & 26 & M & CRS & $\mathrm{OC}$ & - & 44 \\
\hline 24 & $\mathrm{R}$ & 47 & $\mathrm{~F}$ & CRS & - & - & 43 \\
\hline 25 & $\mathrm{~L}$ & 70 & $\mathrm{~F}$ & Mucocele & $\mathrm{OC}$ & - & 41 \\
\hline 26 & $\mathrm{~L}$ & 61 & $\mathrm{~F}$ & CRS & - & - & 40 \\
\hline 27 & $\mathrm{R}$ & 54 & $\mathrm{~F}$ & CRS & - & - & 40 \\
\hline 28 & $\mathrm{~L}$ & 51 & $\mathrm{~F}$ & CRS & - & - & 39 \\
\hline 29 & $\mathrm{~L}$ & 54 & M & CRS & - & - & 39 \\
\hline 30 & $\mathrm{~L}$ & 50 & M & Mucocele & - & - & 37 \\
\hline 31 & $\mathrm{~L}$ & 61 & $\mathrm{M}$ & CRS & $\mathrm{OC}$ & - & 33 \\
\hline 32 & $\mathrm{R}$ & 55 & $\mathrm{~F}$ & CRS & - & - & 32 \\
\hline 33 & $\mathrm{~L}$ & 78 & $\mathrm{M}$ & IP & - & - & 30 \\
\hline 34 & $\mathrm{~L}$ & 44 & $\mathrm{~F}$ & CRS & - & - & 29 \\
\hline 35 & $\mathrm{R}$ & 30 & $\mathrm{~F}$ & Mucocele & OC & - & 29 \\
\hline 36 & $\mathrm{R}$ & 55 & M & CRS & - & - & 27 \\
\hline 37 & $\mathrm{R}$ & 55 & $\mathrm{~F}$ & IP & - & - & 27 \\
\hline 38 & $\mathrm{~L}$ & 29 & $\mathrm{~F}$ & CRS & AFR & - & 24 \\
\hline 39 & $\mathrm{R}$ & 46 & M & CRS & - & - & 24 \\
\hline 40 & $\mathrm{R}$ & 31 & M & CRS & - & - & 23 \\
\hline 41 & $\mathrm{R}$ & 31 & M & CRS & $\mathrm{OC}$ & - & 23 \\
\hline 42 & $\mathrm{~L}$ & 37 & $\mathrm{M}$ & CRS & - & - & 22 \\
\hline 43 & $\mathrm{~L}$ & 47 & $\mathrm{~F}$ & Mucocele & AFR & - & 22 \\
\hline 44 & $\mathrm{~L}$ & 66 & $\mathrm{~F}$ & CRS & - & - & 19 \\
\hline 45 & $\mathrm{R}$ & 19 & M & CRS & AFR, OC & Trephine & 15 \\
\hline 46 & $\mathrm{R}$ & 72 & $\mathrm{~F}$ & CRS & $\mathrm{OC}$ & - & 14 \\
\hline 47 & $\mathrm{R}$ & 49 & M & CRS & - & - & 13 \\
\hline 48 & $\mathrm{~L}$ & 65 & $\mathrm{M}$ & CRS & - & - & 12 \\
\hline 49 & $\mathrm{R}$ & 49 & $\mathrm{M}$ & CRS & - & - & 12 \\
\hline
\end{tabular}

$C R S$ chronic rhinosinusitis, IP inverted papilloma, $O C$ orbit complication, $A F R$ allergic fungal rhinosinusitis 
located on the right side in 22 patients and on the left side in 27 patients. 15 patients had concomitant orbit complication (OC) with 1 case requiring trephine procedure, 3 cases were noted with allergic fungal rhinosinusitis (AFR), and 1 case had malignancy and intracranial invasion of inverted papilloma needing craniotomy.

\section{Surgical outcome}

The LIPF was placed in the inferior part of the nasal cavity and did not disturb the subsequent steps (Fig. 2C). All surgeries were uneventful and no perioperative complications (significant hemorrhage, orbital damage or cerebrospinal fluid leaks) were noted.

This LIPF can reach the frontal recess in 44 of total 49 cases $(89.8 \%)$. In minority $(n=5,10.2 \%)$, the length of the flap may be a little short, but it does not affect clinical outcome, because the flap will quickly grow and cover the little remained exposed bone. The underlying surface of exposed bone reached fast re-epithelialization in 3 months. Minor postoperative complications (non-obstructive synechia) were noted in four patients $(8.16 \%)$. The frontal neo-ostium remained patent in all patients both on endoscopy and on CT scan (Fig. 3) at a follow-up of 12 months. Failure was noted in one patient (2.04\%) for recurrence of inverted papilloma at 21 months follow-up with more than five previous surgeries.

32 patients with recalcitrant CRS were available for at least 1 year of follow-up (mean of 39 months, range 12-65 months). At the 12 months, 25 patients of them were controlled, 7 cases were partly controlled, and no one were uncontrolled. Till the current time of this article, 26 patients

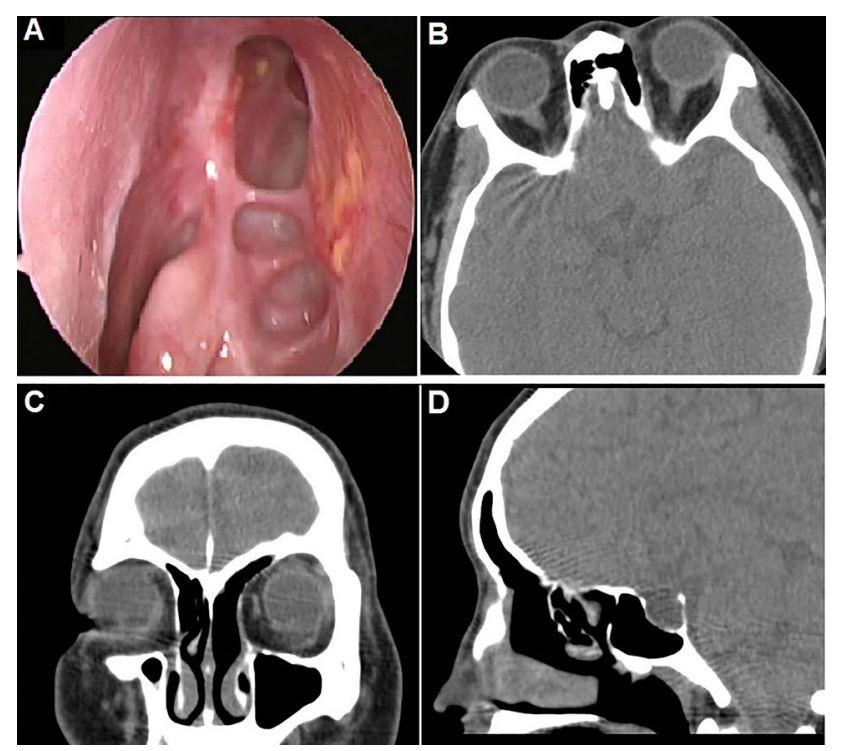

Fig. 3 (A) Endoscopic views, (B) Axial, (C) coronal and (D) sagittal $\mathrm{CT}$ images showing the neo-ostium at 12 months after surgery were controlled, 6 cases were partly controlled, and no one were uncontrolled. The facial pain and total symptom VAS scores after surgeries both decreased significantly when compared with the baseline [baseline: $5(4,7), 11(6,16)$ vs 3 months: $2(1,3), 9(4,11)$ and 12 months: $2(1,3)$, $9(4,11) ; P<0.05]$. The VAS scores of nasal obstruction, rhinorrhea, loss of smell and overall burden did not change significantly $(P>0.05)$. The Lund-McKay endoscopic score decreased significantly $(P<0.05)$ when compared with the baseline [baseline: $4(3,5)$ vs 3 months: $2(2,4)$ and 12 months: $2(1,3) ; P<0.05]$. The detailed data are shown in Table 2.

\section{Discussion}

In this study, we prospectively report the first clinical series of a LIPF technique in Draf IIb procedures and demonstrate its clinical feasibility and efficacy associated with good outcomes in maintaining neo-ostium patency and clinical control of disease, without major complications.

The main techniques that can address advanced frontal sinus pathologies with the main concern maintaining neo-ostium patency are the Draf IIb and Draf III drillings. There is much more evidence concerning the outcome of the Draf III procedure, which is subsequently widely applied in current practice. In a 2017 systematic review and meta-analysis (level 2 evidence) of 29 articles including 1205 patients mainly indicated in chronic frontal sinusitis, mucoceles, tumors and traumas, the overall patency rate after Draf III was $90.7 \%$, and the revision rate was $12.6 \%$ [8]. Despite studies selectively reporting on Draf IIb results in previous literature were limited, several recent studies had showed the safety and efficacy of the Draf IIb procedure. A systematic review of 26 studies by Haddad et al. in 2021 (level 2 evidence) showed that the main indication for Draf IIb was chronic frontal rhinosinusitis (61.82\%), and

Table 2 VAS and Lund-Kennedy scores of patients with recalcitrant CRS

\begin{tabular}{lcll}
\hline & Baseline & 3 months & 1 year \\
\hline VAS score & & & \\
Nasal obstruction & $1(0,2)$ & $1(0,3)$ & $1(0,2)$ \\
Rhinorrhea & $1(0,3)$ & $1(0,3)$ & $1(0,3)$ \\
Facial pain & $5(4,7)$ & $2(1,3)^{*}$ & $2(1,3)^{*}$ \\
Loss of smell & $2(1,4)$ & $2(1,3)$ & $2(1,3)$ \\
Total symptom & $11(6,16)$ & $9(4,11)^{*}$ & $9(4,11)^{*}$ \\
Overall burden & $2(0,3)$ & $2(1,2)$ & $2(1,3)$ \\
Total endoscopic score & $4(3,5)$ & $2(2,4)^{*}$ & $2(1,3)^{*},{ }^{*}$ \\
\hline
\end{tabular}

*Compared with the score of baseline, $P<0.05$

${ }^{\#}$ Compared with the score of 3 months, $P<0.05$ 
the overall postoperative patency rate was $87.85 \%$ whether it was applied for chronic rhinosinusitis or for the other indications [10]. Patel et al. [9] also conducted a comparative cohort study (level 3 evidence) between Draf IIb and Draf III and showed no significant difference in frontal sinus patency rates, revision rates, or complications. These evidences have proved the safety and efficacy of Draf IIb comparable with Draf III, making it a valid option when a bilateral approach is not needed. In this study, all the patients underwent the Draf IIb surgery for unilateral recurrent frontal lesions and the overall outcome was favorable.

Restenosis of frontal neo-ostium is still an issue in the Draf surgery, especially in the case of unilateral Draf IIb procedure. One of the main factors associated with restenosis is related to the resection of mucosa leaving a circumferential surface of exposed drilled bone that may induce osteitis with subsequent neo-osteogenesis and stenosis [11]. Lee suggests that osteitic bone acts as an inflammatory center, initiating edema and hypertrophy of the adjacent mucosa, thus narrowing the frontal recess [23]. Mucosal flaps or free grafts can be used to cover exposed bone to speed up mucosal healing and prevent osteitis.

Covering exposed bone with grafts or flaps was proposed in Draf III with promising results [11, 15, 16, 18, 20]. Recently, several flap techniques have also been reported to improve outcomes in Draf IIb procedures. Grayson et al. [17] applied a nasoseptal flap (NSF) or free graft in 37 patients who had underwent Draf IIb for frontal sinus fractures, and all sinuses were patent on final examination at a mean follow-up of 26 months (level 4 evidence). In Fiorini et al.'s [5] report, a septoturbinal flap (STF) was used for Draf IIb procedures, and postoperative stenosis of the neo-ostium was observed in 1 of 46 patients (level 4 evidence). Khoueir et al. [19] reported on a double-flap technique using a STF and a lateral-based nasoseptal flap (LNSF) to cover the posterior and anterolateral edges of the Draf IIb neo-ostium in eight patients, and no restenosis was noted at a mean follow-up of 3 months (level 4 evidence). In Omura et al.'s study, a superior lateral anterior pedicle (SLAP) flap was applied to Draf IIb procedures in eight cases (level 4 evidence). The neoostium remained patent in all patients, and no complications, such as synechiae or orbital injury, were seen in any of the patients [2]. Though no statistically significant conclusion could be made in Haddad et al.'s systematic review, patency rates after Draf IIb surgery were higher when flaps or grafts were applied $(93.5 \%)$ versus when they were not $(86.7 \%)$ [10]. LIPF is based on the dorsum of the inferior turbinate, and mainly pedicled on branches of the facial and lateral posterior nasal arteries. In this study, the LIPF were used in all the Draf IIb surgeries, allowing fast re-epithelialization and integration with the underlying surface.

The LIPF has several advantages. First, LIPF can be used in patients who previously underwent endoscopic surgery, compared with the aforementioned flaps involving septum or middle turbinal, such as NSF, STF and LNSF. In revision surgeries, the nasal septum and middle turbinal is not always intact. Whereas the lateral nasal wall, especially the mucosa anterior to middle turbinal, is not manipulated in most cases. Second, compared with the SLAP flap raised from the inferior turbinate which is usually thick and not always suitable for maintaining the neo-ostium patency, the LIPF is thinner and more portable, and moreover, the design of LIPF can not only avoid torsion of the pedicle of flap when unfolded to cover the exposed bone, but also maintain the natural drainage outflow of frontal ostium, because the direction of mucociliary flow is orientated in LIPF. Finally, it is mini-invasive and easy to manipulate, and usually does not disturb the operative field.

In this study, our LIPF technique resulted in a high patency rate of $100 \%$ and a good clinical control rate of CRS after at 12 months. A follow-up period of at least 12 months for evaluating ostium patency was chosen for that it was demonstrated that restenosis is an ongoing process during a period of 1 year [13]. Moreover, based on EPOS 2012 [22], the short-term outcome of surgical treatment for CRS was also suggested to be evaluated for at least 1 year, which is consistent with newly published EPOS 2020 [24]. Although final size of the neo-ostium was not exactly measured and failed to compare with the intraoperative size, the ability to visualize into the frontal sinus by endoscopic assessment was able to evaluate the patency of the neo-ostium, which has been applied and validated in various previous studies $[2,9,19,25]$.

In view of this study, we rationally speculated that the LIPF can be applied to advanced frontal sinus pathologies, such as recalcitrant CRS, mucocele, benign tumor and trauma. Theoretically, there are some clinical situations where the LIPF is not suitable: unhealthy mucosa in case of severe polyposis or extensive fibrosis.

This study was level 4 evidence in accordance with the Oxford Centre for Evidence-Based Medicine Levels with some limitations. The first, there was no control group without application of flaps. The second, our patency rate of $100 \%$ and clinical control rate of CRS may be inconsistent with the recent systematic review which showed that the postoperative patency rate of was $93.5 \%$ for Draf IIb with flaps/grafts [10]. However, one previous study from Omura et al. [2] also provided an overall patency rate of $100 \%$ in their cohort, which was in line with our findings. Moreover, nasal nebulization inhalation of budesonide for CRS patients may also contribute to the excellent outcome in addition to the LIPF technique $[21,26]$. The third, a larger sample size and longer follow-up might change outcomes. However, despite of these limitations, our current study suggests that the LIPF technique in the Draf IIb for unilateral recurrent frontal lesions is convenient, safe and effective. 


\section{Conclusion}

The LIPF technique was convenient and applicable to Draf IIb procedures. It could decrease the incidence of restenosis of the frontal sinus drainage pathway and increase the clinical control rate of the disease without main complications. Randomized controlled studies in homogenous groups with larger sample are needed to verify this conclusion.

Acknowledgements No acknowledgements.

Author contributions H-T Zhen designed the study, performed the operations and collected the data. $\mathrm{C} \mathrm{He}$ analyzed and interpreted the data, prepared the manuscript. Both authors read, revised and approved the final manuscript.

Funding No financial support or funding.

Data availability The data that support the findings of this study are available from the corresponding author upon reasonable request.

\section{Declarations}

Conflict of interest No conflict of interest exists.

Ethics approval This study was approved by the ethics committee of Tongji Hospital and conducted with written informed consent from each patient.

Open Access This article is licensed under a Creative Commons Attribution 4.0 International License, which permits use, sharing, adaptation, distribution and reproduction in any medium or format, as long as you give appropriate credit to the original author(s) and the source, provide a link to the Creative Commons licence, and indicate if changes were made. The images or other third party material in this article are included in the article's Creative Commons licence, unless indicated otherwise in a credit line to the material. If material is not included in the article's Creative Commons licence and your intended use is not permitted by statutory regulation or exceeds the permitted use, you will need to obtain permission directly from the copyright holder. To view a copy of this licence, visit http://creativecommons.org/licenses/by/4.0/.

\section{References}

1. Wormald PJ (2003) Salvage frontal sinus surgery: the endoscopic modified Lothrop procedure. Laryngoscope 113:276-283. https:// doi.org/10.1097/00005537-200302000-00015

2. Omura K, Nomura K, Aoki S, Katori Y, Tanaka Y, Otori N (2018) Lacrimal sac exposure and a superior lateral anterior pedicle flap to improve outcomes of Draf type II and III procedures. Int Forum Allergy Rhinol. https://doi.org/10.1002/alr.22122

3. Gross WE, Gross CW, Becker D, Moore D, Phillips D (1995) Modified transnasal endoscopic Lothrop procedure as an alternative to frontal sinus obliteration. Otolaryngol Head Neck Surg 113:427434. https://doi.org/10.1016/s0194-5998(95)70080-3

4. Weber R, Draf W, Kratzsch B, Hosemann W, Schaefer SD (2001) Modern concepts of frontal sinus surgery. Laryngoscope 111:137146. https://doi.org/10.1097/00005537-200101000-00024

5. Fiorini FR, Nogueira C, Verillaud B, Sama A, Herman P (2016) Value of septoturbinal flap in the frontal sinus drill-out type IIb according to draf. Laryngoscope 126:2428-2432. https://doi.org/ 10.1002/lary. 25947

6. Eloy JA, Vazquez A, Liu JK, Baredes S (2016) Endoscopic approaches to the frontal sinus: modifications of the existing techniques and proposed classification. Otolaryngol Clin N Am 49:1007-1018. https://doi.org/10.1016/j.otc.2016.03.023

7. Anderson P, Sindwani R (2009) Safety and efficacy of the endoscopic modified Lothrop procedure: a systematic review and metaanalysis. Laryngoscope 119:1828-1833. https://doi.org/10.1002/ lary. 20565

8. Shih LC, Patel VS, Choby GW, Nakayama T, Hwang PH (2018) Evolution of the endoscopic modified Lothrop procedure: a systematic review and meta-analysis. Laryngoscope 128:317-326. https:// doi.org/10.1002/lary.26794

9. Patel VS, Choby G, Shih L-C, Patel ZM, Nayak JV, Hwang PH (2018) Equivalence in outcomes between Draf 2B vs Draf 3 frontal sinusotomy for refractory chronic frontal rhinosinusitis. Int Forum Allergy Rhinol 8:25-31. https://doi.org/10.1002/alr.22032

10. Haddad R, Khoueir N, Smaily H, Rassi S, Hamad WA (2021) Safety and efficacy of the Draf IIb procedure: a systematic review. Otolaryngol Head Neck Surg. https://doi.org/10.1177/019459982110042 37

11. AlQahtani A, Bignami M, Terranova P et al (2014) Newly designed double-vascularized nasoseptal flap to prevent restenosis after endoscopic modified Lothrop procedure (Draf III): laboratory investigation. Eur Arch Otorhinolaryngol 271:2951-2955. https://doi.org/10. 1007/s00405-014-2961-2

12. Bhandarkar ND, Sautter NB, Kennedy DW, Smith TL (2013) Osteitis in chronic rhinosinusitis: a review of the literature. Int Forum Allergy Rhinol 3:355-363. https://doi.org/10.1002/alr.21118

13. Tran KN, Beule AG, Singal D, Wormald PJ (2007) Frontal ostium restenosis after the endoscopic modified Lothrop procedure. Laryngoscope 117:1457-1462. https://doi.org/10.1097/MLG.0b013e3180 6865be

14. Leung N, Mawby TA, Turner H, Qureishi A (2016) Osteitis and chronic rhinosinusitis: a review of the current literature. Eur Arch Otorhinolaryngol 273:2917-2923. https://doi.org/10.1007/ s00405-015-3817-0

15. Wang YP, Shen PH, Hsieh LC, Wormald PJ (2019) Free mucosal grafts and anterior pedicled flaps to prevent ostium restenosis after endoscopic modified Lothrop (frontal drillout) procedure: a randomized, controlled study. Int Forum Allergy Rhinol 9:1387-1394. https://doi.org/10.1002/alr.22416

16. Hildenbrand T, Wormald PJ, Weber RK (2012) Endoscopic frontal sinus drainage Draf type III with mucosal transplants. Am J Rhinol Allergy 26:148-151. https://doi.org/10.2500/ajra.2012.26.3731

17. Grayson JW, Jeyarajan H, Illing EA, Cho DY, Riley KO, Woodworth BA (2017) Changing the surgical dogma in frontal sinus trauma: transnasal endoscopic repair. Int Forum Allergy Rhinol 7:441-449. https://doi.org/10.1002/alr.21897

18. Illing EA, do Cho Y, Riley KO, Woodworth BA (2016) Draf III mucosal graft technique: long-term results. Int Forum Allergy Rhinol 6:514-517. https://doi.org/10.1002/alr.21708

19. Khoueir N, Verillaud B, Castelnuovo P, Herman P (2018) Value of double mucoperiosteal flaps to prevent restenosis in Draf IIb/III: first clinical report. Clin Otolaryngol 43:746-749. https://doi.org/ 10.1111/coa.13044

20. Seyedhadi S, Mojtaba MA, Shahin B, Hoseinali K (2013) The Draf III septal flap technique: a preliminary report. Am J Otolaryngol 34:399-402. https://doi.org/10.1016/j.amjoto.2013.01.019

21. Zhen H, Peng L, Long $X$ et al (2007) Clinical observation on inhalation of pulmicort in patients with chronic rhinosinusitis after surgery. Lin Chung Er Bi Yan Hou Tou Jing Wai Ke Za Zhi 21:1072-1074

22. Fokkens WJ, Lund VJ, Mullol J et al (2012) European position paper on rhinosinusitis and Nasal Polyps 2012. Rhinol Suppl 23:1-298 
23. Lee JT, Kennedy DW, Palmer JN, Feldman M, Chiu AG (2006) The incidence of concurrent osteitis in patients with chronic rhinosinusitis: a clinicopathological study. Am J Rhinol 20:278-282. https:// doi.org/10.2500/ajr.2006.20.2857

24. Fokkens WJ, Lund VJ, Hopkins C et al (2020) European position paper on rhinosinusitis and Nasal Polyps 2020. Rhinology 58:1-464. https://doi.org/10.4193/Rhin20.600

25. Omura K, Nomura K, Aoki S et al (2019) Effect of a superior lateral anterior pedicle flap for Draf procedures. J Craniofac Surg 30:e350 e352. https://doi.org/10.1097/SCS.0000000000005407

26. Zheng PJ, Zhang YY, Zhang SH, Liu GF, Wang JS (2020) Nasal nebulization inhalation of budesonide for chronic rhinosinusitis with nasal polyps: A protocol for systematic review and meta-analysis. Medicine (Baltimore) 99:e20354. https://doi.org/10.1097/MD. 0000000000020354

Publisher's Note Springer Nature remains neutral with regard to jurisdictional claims in published maps and institutional affiliations. 